\title{
Para uma teoria da avaliação no domínio das aprendizagens
}

\author{
DOMINGOS FERNANDES*
}

\section{RESUMO}

A construção de uma teoria da avaliação no domínio das aprendizagens dos alunos obriga a um esforço de sistematização, de clarificação, de identificação e de compreensão dos seus elementos essenciais e das relações entre eles. Não será fácil apoiar, transformar e desenvolver práticas de avaliação sem uma teoria que as possa enquadrar dos pontos de vista epistemológico, ontológico e metodológico. Mudar e melhorar práticas de avaliação implica que o seu significado seja claro para os diferentes intervenientes e, muito particularmente, para os professores e investigadores. A principal finalidade deste artigo é discutir as seguintes questôes críticas no processo de construção teórica da avaliação no domínio das aprendizagens: a) a integração e/ou articulação de conceitos fundadores das tradiçôes teóricas mais influentes na literatura (a francófona e a anglo-saxónica); b) a conceptualização da avaliação formativa alternativa, integrando os contributos de diferentes tradições teóricas e cujo principal propósito é melhorar as aprendizagens; e c) as relaçóes entre a avaliação sumativa e a avaliação formativa alternativa. $\mathrm{O}$ artigo suscita um conjunto de reflexóes e conclusóes em que se sugerem algumas perspectivas de desenvolvimento na construção teórica da avaliaçáo no domínio das aprendizagens dos alunos.

Palavras-chave: teoria da educação, avaliação da aprendizagem, avaliação da educação, prática de ensino, avaliação do aluno.

\section{RESUMEN}

La construcción de una teoría de la evaluación en el dominio de los aprendizajes de los alumnos obliga a un esfuerzo de sistematización, de clarificación, de identificación y de comprensión de sus elementos esenciales y de las relaciones entre ellos. No será fácil apoyar, transformar y

* Professor Associado com Agregação na Faculdade de Psicologia e de Ciências da Educação da Universidade de Lisboa (dfernandes@fpce.ul.pt). 
desarrollar prácticas de evaluación sin una teoría que las pueda encuadrar desde un punto de vista epistemológico, ontológico y metodológico. Modificar y mejorar prácticas de evaluación implica que su significado esté claro para todos los involucrados y, muy especialmente, para los profesores e investigadores. La principal finalidad de este artículo es discutir las siguientes cuestiones críticas en el proceso de construcción teórica de la evaluación en el dominio de los aprendizajes: a) la integración y/o articulación de conceptos fundadores de las tradiciones teóricas más influyentes en la literatura (la francófona y la anglosajona); b) la conceptualización de la evaluación formativa alternativa, integrando los aportes de diferentes tradiciones teóricas y cuyo principal propósito es mejorar los aprendizajes; y c) las relaciones entre la evaluación sumativa y la evaluación formativa alternativa. El artículo suscita un conjunto de reflexiones y conclusiones en las que se sugieren algunas perspectivas de desarrollo en la construcción teórica de la evaluación en el dominio de los aprendizajes de los alumnos.

Palabras clave: teoría de la educación, evaluación del aprendizaje, evaluación de la educación, práctica de enseñanza, evaluación del alumno.

\section{ABSTRACT}

Constructing an evaluation theory in the domain of student learning demands an effort in systematizing, clarifying, identifying and understanding its essential elements and the relationships between them. It will not be easy to support, transform and develop evaluation practices without a theory that can insert them from an epistemological, ontological and methodological perspective. Changing and improving evaluation practices implies making their meaning clear to the different participants and especially to teachers and researchers. The main objective of this article is to discuss the following critical issues in the process of a theoretical construction of evaluation in the domain of different kinds of learning: a) integrating and/or articulating the founding concepts of the most influential theoretical traditions in the literature (French and Anglo-Saxon); b) conceptualizing alternative formative evaluation, integrating the contributions of different theoretical traditions, whose main purpose is to improve learning; and c) the relationships between summative evaluation and alternative formative evaluation. The article puts forward a set of reflections and conclusions which suggest some development perspectives in the theoretical construction of evaluation in the domain of student learning.

Keywords: theory of education, learning evaluation, education assessment, teaching practice, student assessment. 
A construção teórica no domínio da avaliação dos alunos tem merecido relativamente pouca atenção por parte dos investigadores, embora seja reconhecido por muitos que é uma condição necessária, ainda que não suficiente, para apoiar as práticas escolares naquele domínio (Black; Wiliam, 1998a, 1998b, 2006a, 2006b; Earl, 2003; Fernandes, 2005; Gifford; O’Connor (Ed.), 1992; Gipps, 1994; Gipps; Stobart, 2003; Stiggins; Conklin, 1992).

Os trabalhos de Gipps (1994), de Berlak (1992a, 1992b), de Archbald e Newmann (1992) e, mais recentemente, de Black e Wiliam (2006b), são dos poucos que, de forma explícita e propositada, discutem abertamente o problema da construção teórica da avaliação, ainda que o façam no domínio particular da avaliação formativa. $\mathrm{O}$ autor deste artigo também tem procurado participar nesse debate através de alguns trabalhos recentemente apresentados e publicados (Fernandes, 2006a, 2006b, 2007a, 2007b).

Haverá pelo menos quatro razóes, eventualmente algo contraditórias entre si, que podem explicar esta escassez de trabalhos relativos à produção teórica no domínio da avaliação do que os alunos sabem, que passo de imediato a discutir.

Uma das razóes terá a ver com a dificuldade em integrar numa teoria uma extensa, complexa e muito diversificada teia de contributos, todos supostamente relevantes. De facto, numa teoria da chamada avaliação dos alunos, é preciso ter em conta teorias curriculares e das aprendizagens e outros contributos que vão desde as perspectivas sociológicas, psicológicas, antropológicas e filosóficas, até às que se relacionam com a comunicação, a ética e a política. Ora, de algum modo, pode ser desencorajador para um investigador ter que enfrentar tantos edifícios teóricos e, após um enorme esforço de investigaçáo, discernimento e de integraçáo, vir eventualmente a constatar que, entretanto, surgiram mais contributos teóricos que não foram considerados. Esta questão não é propriamente nova no domínio da investigação: o dilema da sucessiva chegada de novos companheiros ao terreno, cada um deles com um contributo mais importante do que o anterior, tornando as coisas praticamente insustentáveis. No entanto, esta lógica da adição não deverá impedir que os investigadores façam os seus juízos acerca do que é essencial e do que é acessório ou até inútil.

Uma outra razão estará eventualmente relacionada com a ideia de que a teoria se vai construindo através da interacção com as práticas e com as realidades educativas, da construção e reconstrução de investigações empíricas, das análises e das integraçóes e relaçóes que se vão descobrindo e interpretando. Neste sentido, a teoria vai surgindo implícita e naturalmente através da integração e do discernimento que 
vamos sendo capazes de fazer e que nos permite consolidar ou rejeitar certas análises e procedimentos práticos. Nestas condiçôes, a construção teórica é entendida como algo que surge naturalmente, não se sentindo necessidade de a preparar deliberadamente, de a racionalizar ou de a tornar explícita.

Uma terceira ordem de razões para este défice de investimento explícito na construção de uma teoria da avaliaçáo no domínio das aprendizagens pode estar relacionada com as perspectivas epistemológicas, filosóficas ou mesmo ideológicas dos investigadores. De facto, alguns poderão sustentar que a teoria não é, de forma alguma, uma prioridade, pois, qualquer que ela seja, terá um impacto nulo, ou muito limitado, no desenvolvimento das práticas. Poderão ainda acrescentar que se pode fazer boa avaliação formativa ou sumativa sem o apoio de qualquer teoria. Outros poderão considerar que não fará sentido construir uma teoria da avaliaçáo na área das aprendizagens sem uma teoria mais geral da avaliação em educação. E ainda outros dirão que, qualquer teoria da avaliação para as aprendizagens, das aprendizagens ou de ambas, será mais um elemento de controlo e de manipulação dos professores e dos alunos, limitando assim a sua livre iniciativa, a sua autonomia e o seu espaço de liberdade pedagógica.

Finalmente, penso que há ainda outra razão, directamente decorrente das políticas educativas de muitos países que, em geral, dão mais relevância às avaliaçóes externas e bastante menos às avaliações internas que ocorrem dentro das salas de aula. Consequentemente, pode ser mais atractivo e estimulante investir nas teorias relacionadas com a concepção e desenvolvimento das avaliações sumativas externas (e.g., teoria de resposta aos itens, modelos teóricos de interpretação de dados).

O pressuposto que está subjacente à discussão desenvolvida neste artigo é a de que uma teoria da avaliação no domínio das aprendizagens pode constituir um importante e indispensável ponto de orientação para professores e investigadores. $\mathrm{Na}$ realidade, há problemas que têm que ser encarados que vão desde um certo caos terminológico e concepçóes confusas, ou mesmo erróneas, acerca de conceitos básicos, até à falta de integração do que hoje já conhecemos no domínio da avaliaçáo formativa e da avaliação sumativa. Uma das funçôes da teoria é a de nos ajudar a discernir onde está o quê, para onde é que se está a caminhar e como é que se está a progredir.

A construção de uma teoria da avaliação no domínio das aprendizagens dos alunos obriga a um esforço de sistematização, de clarificação, de identificação e de compreensão dos seus elementos essenciais e das relaçóes entre eles. Não será fácil apoiar, transformar e desenvolver práticas de avaliação sem uma teoria que as possa enquadrar dos 
pontos de vista epistemológico, ontológico e metodológico. Mudar e melhorar práticas de avaliação implica que o seu significado seja claro para os diferentes intervenientes e, muito particularmente, para os professores e investigadores.

A principal finalidade deste artigo é identificar e discutir algumas questôes consideradas críticas no processo de construção teórica da avaliação no domínio das aprendizagens. As questôes críticas são as que se consideram incontornáveis na construção teórica, representando, simultaneamente, áreas de dificuldade, ou áreas problemáticas, que é preciso compreender mais profundamente.

O artigo é exploratório por natureza e tem um âmbito reduzido, limitando-se a abordar as seguintes questôes críticas: a) a necessidade de integrar e/ou articular alguns dos conceitos fundadores das tradiçóes teóricas mais influentes na literatura (a francófona e a anglo-saxónica); b) a necessidade de clarificação conceptual que passa pela conceptualização da avaliação formativa alternativa para identificar toda a avaliação cujo principal propósito é melhorar as aprendizagens, integrando os contributos de diferentes tradiçóes teóricas; e c) a necessidade de compreender as relações entre a avaliação sumativa e a avaliação formativa alternativa.

$\mathrm{O}$ artigo termina com um conjunto de reflexóes e conclusôes em que se sugerem algumas perspectivas de desenvolvimento na construção teórica da avaliação no domínio das aprendizagens dos alunos.

\section{UMA DISCUSSÃO ACERCA DE DUAS TRADIÇÕES TEÓRICAS}

O desenvolvimento e a consolidação de uma teoria da avaliação no domínio das aprendizagens e, em particular, de uma teoria da avaliação formativa, deverá passar por um significativo esforço de integração das tradiçóes teóricas existentes, contrariando a cristalizaçáo das ideias em dicotomias cuja única vantagem parece ser a de nos alertarem para a necessidade de se construírem perspectivas mais abrangentes, mais integradoras e mais dialécticas. Isto é, com mais potencial para nos ajudar a compreender os fenómenos de interesse.

A tradição francófona e a tradição anglo-saxónica (prefere-se esta expressão em vez de anglófona uma vez que há anglófonos que não são anglo-saxónicos) são as que têm mais predominância na literatura referente à avaliação dos alunos. Por isso se decidiu fazer uma análise e uma reflexão, ainda que sucintas, acerca de cada uma destas tradiçóes teóricas.

$\mathrm{Na}$ tradição francófona de investigação a avaliação formativa é uma fonte de regulação dos processos de aprendizagem e dos processos de ensino. A regulação é 
o seu conceito chave, associado aos processos internos, cognitivos e metacognitivos, dos alunos, como é o caso do auto-controlo, da auto-avaliação ou da auto-regulação (e.g., Bonniol, 1989; Cardinet, 1991; Grégoire, 1996; Perrenoud, 1998a, 1998b). Na tradição anglo-saxónica o conceito chave é o feedback que surge associado às múltiplas interacções sociais e culturais que ocorrem nos processos de ensino e de aprendizagem (e.g., Black; Wiliam, 1998a, 1998b, 2006a, 2006b; Gipps, 1994, 1999; Gipps; Stobart, 2003; Shepard, 2001; Stiggins, 2004).

Os investigadores francófonos têm desenvolvido perspectivas teóricas baseadas nos processos cognitivos e metacognitivos dos alunos e em modelos de ensino e de aprendizagem que procuram enquadrar sistemicamente as situaçóes. Nesta perspectiva, interessa sobretudo estudar como é que os alunos aprendem, a partir das teorias que se conhecem, para que se utilize uma avaliação formativa que os ajude a regular autonomamente a aprendizagem. Neste caso, o feedback é um elemento a considerar sem que, no entanto, ocupe o lugar de destaque que lhe é atribuído pelos autores anglo-saxónicos. Sustenta-se que a presença do feedback náo garante, por si só, uma adequada orientaçáo para as aprendizagens e que estas são influenciadas por outros factores importantes (por exemplo, a natureza das tarefas e os processos de regulação utilizados por professores e alunos). Além disso, considera-se que nem toda a regulação dos processos de aprendizagem passa pela avaliação formativa (ver, por exemplo, Perrenoud, 1998b). O que, de facto, parece mais essencial é compreender os processos cognitivos e metacognitivos dos alunos para que, a partir daí, se possa intervir para que eles regulem as suas aprendizagens. Assim, os alunos têm um papel mais central, mais destacado e mais autónomo pois, em última análise, a avaliação formativa funciona quase como um processo de auto-avaliação em que a interferência do professor é reduzida ao mínimo. $\mathrm{Ou}$ seja, na perspectiva francófona, os professores promovem uma regulação interactiva, transferindo para os alunos a tarefa de se responsabilizarem pelas suas próprias aprendizagens através do desenvolvimento da auto-avaliaçáo e do conhecimento das finalidades que têm que atingir.

Perrenoud (1998a) refere que os alunos, utilizando adequadamente a auto-avaliação, são capazes de regular as suas aprendizagens e só precisam da colaboração dos professores como recurso pontual e esporádico. É uma perspectiva influenciada pelas teorias sociocognitivas, orientada para a construção de modelos teóricos das aprendizagens e que, ainda de acordo com Perrenoud (1998b), está num certo impasse teórico e metodológico. Nestas condiçóes, talvez possamos afirmar que é uma perspectiva teórica com algumas dificuldades de concretização dada a natureza 
dos processos envolvidos e do seu enquadramento teórico (por exemplo, teorias da metacognição, teorias da aprendizagem). Perrenoud (1998a) chega mesmo a afirmar que, nas circunstâncias que se vivem nos sistemas educativos contemporâneos, é bastante difícil criar condiçóes que facilitem a regulação.

Os investigadores anglo-saxónicos abordam as questóes da avaliação formativa com base no apoio que os professores podem prestar aos alunos na resoluçáo de tarefas e nas aprendizagens previstas no currículo. Ou seja, a avaliação formativa é vista como um processo eminentemente pedagógico, muito orientado e controlado pelos professores, destinado a melhorar as aprendizagens dos alunos. Talvez por isto mesmo o feedback seja um conceito central na visão anglo-saxónica de avaliação formativa, chegando mesmo a confundir-se com esta, pois é através dele que os professores comunicam aos alunos o seu estado em relação às aprendizagens e as orientaçóes que, supostamente, os ajudarão a ultrapassar eventuais dificuldades (Sadler, $1989,1998)$. Tendo os professores um maior protagonismo, as coisas parecem estar mais dependentes dos seus pensamentos e acçóes do que dos pensamentos e acçóes dos alunos. Por exemplo, a auto-avaliação, apesar de ser um processo do aluno, aparece bastante associada às orientaçóes e apoios que os professores proporcionam durante as aulas.

Para os investigadores anglo-saxónicos, a avaliação formativa é referida como um processo determinante na melhoria dos resultados dos alunos através da utilização de tarefas que interpretem as exigências do currículo. Ou seja, nesta perspectiva há uma relaçáo explícita entre a avaliação formativa e um referencial curricular bem determinado; nessa relação os professores assumem o controlo de uma diversidade de incumbências tais como a identificação de domínios do currículo, a selecção de uma variedade de tarefas e de estratégias de avaliação e a planificação do ensino em geral.

Em suma, trata-se de uma visão pragmática e pedagógica da avaliação formativa, inspirada nas teorias socioculturais. De facto, o funcionamento e regulaçáo dos processos de interacçáo pedagógica e, consequentemente, de todos os processos de comunicação que se estabelecem nas salas de aula constituem uma preocupaçáo central na perspectiva anglo-saxónica (Gipps, 1999; Shepard, 2000). Neste sentido, há um esforço de aproximação às realidades vividas nas salas de aula e uma preocupação em identificar e resolver problemas imediatos e concretos. Talvez por isso mesmo, na perspectiva anglo-saxónica, a construção teórica esteja baseada uma significativa base empírica (e.g., Black; Wiliam, 1998a, 1998b, 2006a, 2006b; Gardner, 2006a; Gipps, 1994; Stiggins; Conklin, 1992). 
A partir destas duas tradiçôes teóricas, emergem pelo menos duas constataçôes significativas. A primeira tem a ver com a sugestão francófona de relativizar o papel do feedback que, por si só, não garante o desenvolvimento das aprendizagens. Os investigadores francófonos referem que é preciso ter em conta outros elementos tais como as relaçóes do feedback com os processos de ensino e com o desenvolvimento dos processos cognitivos e sócio-afectivos dos alunos. Assim, o feedback deverá ter um enquadramento teórico mais amplo e não se reduzir a um processo quase mecânico de orientação dos alunos para um espectro mais ou menos limitado de aprendizagens. (Para uma discussão aprofundada sobre o conceito de feedback e sobre o seu papel no domínio da avaliação ver, por exemplo, Vieira, 2007.)

A segunda tem a ver com a sugestão anglo-saxónica acerca do papel relevante que o professor deve ter no desenvolvimento do currículo, criando oportunidades para que as interacçóes sociais se desenvolvam. O professor deverá ter um papel essencial no desenvolvimento da interacção com todos e com cada um dos alunos e entre os próprios alunos, pois a avaliação só pode assumir a sua natureza formativa num contexto interactivo. A auto-avaliação e a consciência dos alunos acerca do seu estado relativamente às finalidades a alcançar no domínio das aprendizagens, desenvolvem-se precisamente em contextos dinâmicos de interacção social.

As características destas duas tradições teóricas suscitam a questão crítica da possível integração e/ou articulação de alguns dos seus conceitos fundadores. A avaliação formativa alternativa, que se discute na secção seguinte, poderá constituir uma possível concretização teórica e prática dessa possível integração e/ou articulaçáo.

\section{AVALIAÇÃO FORMATIVA ALTERNATIVA: PERSPECTIVAS DE CLARIFICAÇÃO E DE ARTICULAÇÃO}

A expressão avaliação alternativa tem sido utilizada na literatura para designar processos de avaliação que não sejam essencialmente baseado em testes de papel e lápis (e.g., Archbald; Newmann, 1992; Berlak, 1992a, 1992b; Gipps, 1994; Gipps; Stobart, 2003). Trata-se de uma designação que, em geral, se refere à avaliação formativa de inspiração cognitivista, mas a verdade é que é demasiado vaga, não contribuindo para a clarificaçáo conceptual que se deseja. Na verdade, pode referirse a uma avaliação em que se diversificam estratégias de recolha de informaçáo sem que, apesar disso, nada de relevante se altere em aspectos tais como as interacçóes professor-aluno ou aluno-aluno, a auto-avaliação, a auto-regulação ou a integraçáo da avaliação nos processos de ensino e aprendizagem. Mas também pode referir-se 
a um tipo de avaliação que valoriza especialmente os processos e os contextos de ensino e aprendizagem.

Talvez como resultado da ambiguidade daquela expressão, abundam na literatura designaçóes associadas a avaliaçóes cujo propósito é melhorar o ensino e as aprendizagens, tais como: avaliação autêntica (Tellez, 1996; Wiggins, 1989a, 1989b, 1998); avaliação contextualizada (Berlak, 1992a, 1992b); avaliação formadora (Abrecht, 1991; Nunziati, 1990); avaliação reguladora (Allal, 1986; Perrenoud, 1998a, 1998b); regulaçâo controlada dos processos de aprendizagem (Perrenoud, 1998a); e avaliação educativa (Gipps, 1994; Gipps; Stobart, 2003; Wiggins, 1998). Independentemente das características particulares de cada uma, todas estas designaçóes se referem a avaliaçóes orientadas para melhorar as aprendizagens, integradas no ensino, na aprendizagem e contextualizadas e em que os alunos são incentivados a participar. Assim, todas são alternativas a avaliaçóes que dão ênfase à classificação, à selecção e à certificação, aos resultados obtidos pelos alunos, à utilização sumativa dos resultados dos testes ou à prestação de contas.

Analisando as características de cada um daqueles tipos de avaliação, verificamos que todas são alternativas à avaliação formativa de natureza behaviourista, identificada com a chamada regulação retroactiva das aprendizagens, uma vez que as dificuldades dos alunos não são detectadas durante, mas sim após, o processo de ensino-aprendizagem (Allal, 1986). Deste modo, temos uma variedade de avaliaçóes alternativas que, no essencial, partilham a sua natureza formativa. Nestas condiçóes, será mais apropriado utilizar a expressão Avaliação Formativa Alternativa (AFA) em vez de Avaliação Alternativa ou de qualquer uma das outras designaçóes referidas. Ao destacar as designaçóes Formativa e Alternativa, sublinha-se o facto de estarmos perante uma avaliação cuja função é melhorar as aprendizagens e o ensino e que é verdadeiramente alternativa à avaliação formativa de inspiração behaviourista e a todo o tipo de avaliaçóes indiferenciadas ditas de intenção ou de vontade formativa (Hadji, 1992). Por estas razóes, a designação avaliação formativa alternativa (AFA) parece responder melhor à necessidade de clarificação que aqui se vem advogando. (Sempre que, ao longo deste artigo, se utilizar a expressão avaliação formativa, é no sentido que aqui se atribui à avaliaçáo formativa alternativa.)

É óbvio que as designaçóes estão normalmente associadas a conteúdos, a significados e a epistemologias que interessa clarificar. Ao procurar agregar uma diversidade de designaçóes a AFA procura também, inevitavelmente, integrar perspectivas e contributos de diferentes tradiçóes teóricas, nomeadamente as francófonas e as anglo-saxónicas. 
A AFA deve permitir que, num dado momento, se conheçam bem os saberes, as atitudes, as capacidades e o estádio de desenvolvimento dos alunos, ao mesmo tempo que lhes deve proporcionar indicaçóes claras acerca do que é necessário fazer para progredir. No caso de ser necessário corrigir algo ou de melhorar as aprendizagens, torna-se imperativo que professores e alunos partilhem as mesmas ideias, ou ideias aproximadas, acerca da qualidade do que se pretende alcançar. Consequentemente, um processo importante é o de regular a qualidade do trabalho que está a ser desenvolvido, utilizando, nomeadamente, um conjunto de recursos cognitivos e metacognitivos que ajudem a eliminar qualquer eventual distância entre as aprendizagens reais e as aprendizagens previstas ou propostas. De facto, tal como refere Biggs (1998), só poderemos dizer que uma avaliação é realmente formativa se, através dela, os alunos se consciencializarem das eventuais diferenças entre o seu estado presente e o estado que se deve alcançar e do que é necessário fazer para as reduzir ou mesmo eliminar. Perrenoud (1998a, 1998b) enquadra-se nesta perspectiva ao afirmar que toda a avaliação que contribui para a regulação das aprendizagens é formativa.

Para clarificar a natureza e funções da AFA, integrando diferentes contributos teóricos, é oportuno sistematizar nesta altura algumas das suas características mais relevantes, tais como:

1. A avaliação é deliberadamente organizada em estreita relação com um feedback inteligente, diversificado, bem distribuído, frequente e de elevada qualidade tendo em vista apoiar e orientar os alunos no processo de aprendizagem.

2. O feedback é importante para activar os processos cognitivos e metacognitivos dos alunos, que, por sua vez, regulam e controlam os processos de aprendizagem, assim como para melhorar a sua motivação e autoestima.

3. A natureza da interacção e da comunicação entre professores e alunos é central porque os professores têm que estabelecer pontes entre o que se considera ser importante aprender e o complexo mundo dos alunos (por exemplo, o que eles são, o que sabem, como pensam, como aprendem, o que sentem e como sentem).

4. Os alunos são deliberada, activa e sistematicamente envolvidos no processo do ensino-aprendizagem, responsabilizando-se pelas suas aprendizagens e tendo amplas oportunidades para elaborarem as suas respostas e para partilharem o que e como compreenderam. 
5. As tarefas propostas aos alunos que, desejavelmente, são simultaneamente de ensino, de avaliação e de aprendizagem, são criteriosamente seleccionadas e diversificadas, representam os domínios estruturantes do currículo e activam os processos mais complexos do pensamento (por exemplo, analisar, sintetizar, avaliar, relacionar, integrar, seleccionar).

6. As tarefas reflectem uma estreita relação entre as didácticas específicas das disciplinas e a avaliação que tem um papel relevante na regulação dos processos de aprendizagem.

7. O ambiente de avaliação das salas de aula induz uma cultura positiva de sucesso baseada no princípio de que todos os alunos podem aprender.

É uma avaliaçáo formativa com este tipo de características que, de acordo com os resultados da investigação, pode permitir melhorar significativamente as aprendizagens dos alunos (e.g., Black; Wiliam, 1998a, 1998b; 2006a; Shepard, 2001; Stiggins, 2002, 2004). Trata-se de uma avaliação para as aprendizagens, porque é deliberadamente organizada para ajudar os alunos a aprender mais e, sobretudo, melhor, através de uma diversidade de processos que incorporam o feedback e a regulação das aprendizagens. A AFA é uma construção social, um processo intrinsecamente pedagógico e didáctico, plenamente integrado no ensino e na aprendizagem, deliberado e interactivo, cuja principal função é regular e melhorar as aprendizagens dos alunos. Ou seja, é conseguir que os alunos aprendam melhor, com significado e compreensão, utilizando e desenvolvendo as suas competências, nomeadamente as do domínio cognitivo e metacognitivo. Nestas condiçôes, a AFA pressupóe uma partilha de responsabilidades em matéria de ensino, avaliaçáo e aprendizagens e, consequentemente, uma redefinição dos papéis dos alunos e dos professores. Além disso, pressupóe novas visões relativamente à natureza das diferentes interacçóes sociais que se podem estabelecer nas salas de aula e dos seus papéis no desenvolvimento da aprendizagem. Obviamente, os professores poderáo ter um papel que deve ser preponderante em aspectos tais como a selecçáo de tarefas ou a organização e distribuição do processo de feedback, enquanto os alunos poderão ter um papel mais activo no desenvolvimento dos processos que se referem à auto-avaliação e à auto-regulação do que têm que aprender.

Interessa agora discutir outra questão crítica que parece fundamental no processo de construção teórica e que diz respeito às relações entre a avaliação formativa alternativa e a avaliação sumativa. 


\section{ACERCA DAS RELAÇÕES ENTRE A AVALIAÇÃO FORMATIVA ALTERNATIVA E A AVALIAÇÃO SUMATIVA}

Recentemente vários autores têm vindo a utilizar as designações "avaliação das aprendizagens" e "avaliação para as aprendizagens" com o mesmo significado das designaçôes "avaliação sumativa" e "avaliação formativa", respectivamente (e.g., Black; Wiliam, 2006a; Gardner, 2006a, 2006b; Harlen, 2006; Sebba, 2006). No primeiro caso os objectos de avaliação são resultados da aprendizagem dos alunos e, por isso mesmo, a avaliação sumativa, ou a avaliação das aprendizagens, ocorre após o desenvolvimento de uma ou mais unidades curriculares. No segundo caso, os objectos preferenciais são os processos de aprendizagem e, por consequência, a avaliação formativa, ou avaliação para as aprendizagens, ocorre durante o desenvolvimento do currículo. Assim, a avaliação formativa tem como finalidade principal melhorar as aprendizagens dos alunos através de uma criteriosa utilização da informação recolhida para que se possam perspectivar e planear os passos seguintes. Por seu lado, a avaliação sumativa faz uma súmula do que os alunos sabem e são capazes de fazer num dado momento. Nuns casos pode ter uma utilizaçáo formativa, contribuindo para regular as aprendizagens e o ensino, mas, em geral, é utilizada para atribuir classificaçôes.

A avaliação formativa está associada a formas de regulação e de auto-regulação que influenciam de forma imediata os processos de ensino e aprendizagem enquanto a avaliação sumativa, em geral, proporciona informação sintetizada que se destina a registar e a tornar público o que parece ter sido aprendido pelos alunos.

A questão das relaçóes entre a avaliação formativa e a avaliação sumativa ou, se quisermos, entre a avaliação para as aprendizagens e a avaliação das aprendizagens continua a suscitar o interesse dos investigadores, quer no domínio da reflexão e construção teóricas, quer no domínio da investigação empírica, quer ainda no domínio das práticas e da planificaçáo curriculares (e. g., Biggs, 1998; Fernandes, 2006a, 2007a; Harlen 2005, 2006; Harlen; James, 1997).

É geralmente reconhecido que avaliação formativa tem uma dupla natureza. É criterial quando as aprendizagens dos alunos se analisam em termos de critérios mais ou menos específicos, previamente definidos, não sendo assim comparadas com algum padrão ou norma. É ipsativa quando as aprendizagens dos alunos são analisadas tendo como referência os próprios alunos. Dito de outro modo, comparam-se os alunos consigo mesmos, tendo muitas vezes em conta aspectos tais como o esforço, o interesse e os progressos alcançados.

Relativamente à avaliaçáo sumativa, diz-se que é criterial, como a avaliação formativa, mas também é normativa, porque compara as aprendizagens dos alunos 
com uma norma (uma média, por exemplo) ou com as aprendizagens de um dado grupo. A partir destes pressupostos, para muitos autores, há necessariamente uma articulação entre as duas modalidades de avaliação porque, no mínimo, ambas partilham a sua natureza criterial; isto é, ambas se organizam, pelo menos em parte, com base num conjunto de critérios (ver, por exemplo, Harlen, 2006).

A propósito destas consideraçóes interessa reflectir acerca de questóes tais como:

1. Será que a avaliação formativa terá sempre necessariamente uma natureza criterial? Ou poderá orientar-se antes por referentes mais abrangentes e complexos que definam e enquadrem o que é importante aprender?

2. Quando se considera que a avaliação formativa é de natureza criterial de que avaliação formativa estaremos realmente a falar? Quais as suas características?

3. Partindo do princípio que a avaliação formativa é criterial haverá ou não diferenças na utilização dos critérios com a avaliação sumativa? Qual será o real sentido deste tipo de concepção?

4. Será que a avaliação formativa não terá também, em certas circunstâncias, uma natureza normativa. Ou seja, será que, nas práticas de avaliação formativa, as comparaçóes com outros alunos, ou com algum tipo de norma, estão irremediavelmente ausentes?

São questôes que merecem discussão aprofundada, tanto quanto possível sustentada em investigação empírica e que, não sendo possível desenvolver neste contexto, aqui se deixam como desafio aos leitores.

No trabalho mais recente de Harlen $(2005,2006)$ é possível identificar quatro preocupaçóes principais: a) definir avaliação formativa, que é identificada com avaliação para as aprendizagens; b) definir avaliação sumativa, que é identificada com avaliação das aprendizagens; c) discutir se os dados da avaliação sumativa podem ser usados na avaliação formativa e vice-versa; e d) discutir se a avaliação formativa e a avaliação sumativa são duas dimensóes diferentes de um mesmo constructo ou se, pelo contrário, são dois conceitos distintos (visão dicotómica).

Apesar de reconhecer que a avaliação das aprendizagens e a avaliação para as aprendizagens são processos conceptualmente diferentes, Wynne Harlen acaba por considerar que, na prática, tais diferenças náo serão táo evidentes, questionando se a informação recolhida com propósitos sumativos pode ser utilizada para fins formativos e vice-versa. A autora acaba por concluir que é complicado utilizar os dados 
produzidos no âmbito da avaliação sumativa para efeitos formativos, uma vez que as avaliaçôes sumativas se destinam a sintetizar as aprendizagens dos alunos com base em critérios gerais, não têm normalmente o propósito de identificar e de orientar os passos a dar a seguir e, tipicamente, ocorrem com pouca frequência. Nestas condiçóes, é evidente que as avaliaçóes sumativas não preenchem os exigentes requisitos das avaliaçôes formativas.

Apesar daquelas consideraçóes, parece óbvio que os testes, como quaisquer instrumentos ou técnicas utilizados no contexto de avaliaçóes sumativas, podem ser utilizados para desenvolver tarefas de natureza formativa. Realmente pode pedir-se aos alunos que formulem questóes para um teste ou que reflictam, individualmente ou em grupo, sobre as suas respostas. Além disso, os resultados de um teste podem ser utilizados para apoiar e melhorar as aprendizagens e o tipo e a natureza do feedback proporcionado pode também ir nesse sentido.

Quanto à utilização das avaliações formativas para fins sumativos Harlen (2005, 2006) vê essa possibilidade embora sem grande entusiasmo pois, no fundo, argumenta que as avaliações formativas têm problemas vários de validade e de fiabilidade porque são desenvolvidas em contextos muito específicos, faltando-lhes, por isso, consistência para que possam servir propósitos sumativos. Porém, a possibilidade não é completamente posta de lado desde que se faça a distinção entre as evidências de aprendizagem e as interpretaçóes que se fazem a partir delas. Para efeitos de avaliação formativa as evidências são interpretadas localmente, no contexto da sala de aula, e destinam-se a tomar decisóes imediatas que têm a ver com o que fazer a seguir naquele mesmo contexto. Para efeitos de avaliação sumativa as evidências devem ser interpretadas com base em critérios mais gerais, iguais para todos os alunos, tendo em conta que a atribuição de classificaçôes finais deve ser feita da forma mais válida e fiável possível.

Trata-se de uma perspectiva que pode ser questionada porque remete a avaliaçáo formativa para a realização de tarefas muito específicas e localizadas que não têm em conta as grandes finalidades do ensino e da aprendizagem. Ora, se é verdade que a avaliação formativa pode e deve ser específica e situada num dado contexto, até para que possa diferenciar os apoios aos alunos que necessitam de vencer certas dificuldades, também é verdade que as tarefas seleccionadas devem ser estruturantes. Isto é, devem ter em conta as tais grandes finalidades e promover a mobilização, a integração, a utilização e a aplicaçáo de uma variedade de conhecimentos, capacidades e atitudes, entretanto desenvolvidos através de vários domínios do currículo. $\mathrm{O}$ problema de Harlen reside na sua falta de confiança na validade e na fiabilidade das 
avaliaçóes formativas, pois parece considerar que só as avaliaçóes sumativas poderão ter a qualidade que garanta uma justa atribuição de classificaçóes aos alunos ou uma adequada comparação entre as suas aprendizagens.

Julgo que será legítimo questionar se as avaliaçôes sumativas internas cumprirão os requisitos de validade e fiabilidade que lhes parecem ser atribuídos. E, de acordo com vários investigadores, o mesmo se poderá dizer relativamente a avaliaçóes sumativas externas do tipo dos exames ou das provas usadas em estudos internacionais (e.g., Goldstein, 2004; Kellaghan, 2003; Riley; Torrance, 2003). Estes problemas são críticos e parecem ainda longe de estar clarificados. É necessário ter presente que a qualidade das avaliaçóes formativas e sumativas internas continua a ser avaliada através de conceitos clássicos da psicometria (validade e fiabilidade) muito utilizados em avaliaçóes de larga escala (e.g., exames nacionais, estudos internacionais). Notese que, em geral, as avaliaçóes sumativas internas e externas são substancialmente diferentes na forma, no conteúdo e nos propósitos. Apesar de tudo isto e das influências evidentes do cognitivismo nas concepçóes emergentes de avaliação, a verdade é que ainda não há teoria que nos proporcione conceitos mais adequados do que a validade e a fiabilidade para analisar a qualidade das perspectivas contemporâneas de avaliação. É, claramente, uma área em aberto a necessitar de novos desenvolvimentos teóricos.

$\mathrm{Na}$ análise das complexas relaçóes entre a avaliação formativa e a avaliação sumativa podem considerar-se, pelo menos, três perspectivas que passo a discutir brevemente.

Uma perspectiva é a de considerar que a avaliação formativa e a avaliação sumativa são conceitos dicotómicos, opostos, com relaçóes muito distintas com os diversos intervenientes e com objectos, finalidades e funçóes de avaliação também diferentes. Produzem tipos de conhecimento diversos e, por isso, estáo baseados em diferentes epistemologias, nada tendo de comum entre si.

Outra perspectiva é a de as considerar como duas dimensóes do mesmo constructo (Harlen, 2006). Assim, teríamos uma espécie de continuum de dimensóes de avaliação situadas entre dois pólos extremos: a avaliação formativa informal (uma espécie de avaliação formativa pura ou ingénua) e a avaliação sumativa formal. Entre estes dois pólos estão a avaliação formativa formal e a avaliação sumativa informal cujos propósitos e práticas apresentam semelhanças várias. Este facto pode suscitar um problema que é o de saber quando é que estamos em presença de uma avaliação formativa formal ou de uma avaliaçáo sumativa informal. Harlen náo faz esta discussão e é compreensível que assim tenha acontecido porque a questáo dificilmente 
se poderá resolver. Tanto quanto é possível perceber-se haverá um conjunto de práticas de avaliação que não são propriamente formativas nem sumativas, mas que poderão ter características híbridas. Poderão mesmo ser outra coisa, uma outra avaliação. Estamos pois em presença de um problema que consiste em saber se existe e como se caracteriza o tipo de avaliação que poderá estar entre a avaliação formativa e a avaliação sumativa. Penso que não será difícil aceitar a ideia de que haverá outros tipos de avaliação que não correspondem exactamente às características e aos propósitos daquelas duas modalidades de avaliação. O problema reside em investigá-los, em caracterizá-los e em identificar as práticas que lhes correspondem.

Finalmente, uma outra perspectiva consiste em considerar que a avaliação para as aprendizagens e a avaliação das aprendizagens são complementares. Neste sentido, podem considerar-se dois conceitos distintos um do outro, importando prosseguir no aprofundamento das suas diferenças para que se clarifiquem objectos, funções, métodos, processos e produtos de cada uma. Desta forma poderão igualmente clarificar-se as suas semelhanças. Porém, não são dicotómicos porque são emanaçôes do conceito de avaliação na sua acepção mais geral e, nesse sentido, partilham aspectos comuns, tais como a recolha de informação para analisar o que os alunos sabem e são capazes de fazer, a formulação de juízos relativos às suas aprendizagens, a utilização de referenciais comuns ou a necessidade de tomar decisóes como consequência das informaçóes obtidas. Poderá ser menos complicado considerá-las como duas dimensóes do mesmo constructo mas ainda é necessário um esforço de clarificaçáo que nos ajude a distinguir claramente entre as duas modalidades de avaliação. Teremos, muito provavelmente, que considerar diferentes tipos de avaliaçóes formativas e sumativas. Por exemplo, se ao fim de algumas aulas em que se trabalhou um determinado conceito se fizer um balanço através de um teste individual, com o fim de analisar o que os alunos sabem, estamos perante uma avaliação sumativa que, à partida, poderá não ter quaisquer funçóes classificativas ou certificativas. Se, na mesma situação, for proporcionado feedback que possa orientar os alunos diferenciadamente, estaremos em presença de uma avaliação formativa de regulação retroactiva que, nesse sentido, não está propriamente integrada no processo de ensino e de aprendizagem. Há pois necessidade de desenvolver investigaçáo que caracterize a variedade de avaliaçóes que ocorrem com frequência nas salas de aula.

A ideia de considerar a avaliação formativa e a avaliação sumativa como complementares baseia-se no pressuposto de que ambas contribuem de formas particulares para avaliar cabalmente o que os alunos sabem e são capazes de fazer. E isto signifi- 
ca, entre outras coisas, que há relações entre ambas que permitem que a informação recolhida para fins formativos possa ser usada para fins sumativos e vice-versa.

Em trabalho anterior, a propósito destes assuntos, formulei a seguinte questão: Que articulaçóes e relaçóes é possível estabelecer entre a avaliação formativa e a avaliação sumativa? (Fernandes, 2005). A resposta preconiza que a avaliação formativa alternativa deve prevalecer nas práticas de sala de aula nos moldes que acima se explicitaram. Além disso, argumenta-se que os dados recolhidos através da avaliação formativa podem e devem ser utilizados pelos professores nas avaliaçóes sumativas internas que são da sua responsabilidade. A avaliação sumativa interna pode assim ser mais diversificada, mais inteligente, mais contextualizada e mais útil para todos os intervenientes, particularmente para os alunos.

Considera-se assim que existe a necessidade prática de promover a articulaçáo entre as duas modalidades de avaliaçáo referindo, no entanto, que uma avaliação sumativa interna de qualidade "deve estar subordinada aos princípios, aos métodos e aos conteúdos da avaliação formativa alternativa” (Fernandes, 2005, p. 75). Este princípio tem um alcance significativo em termos pedagógicos e didácticos e, particularmente, em termos da integração da avaliação formativa com o ensino e com a aprendizagem, permitindo recolher informação válida e fiável (veja-se, por exemplo, Black; Wiliam, 2006c; Stobart, 2006), e envolvendo activamente professores e alunos em todas as etapas fundamentais do desenvolvimento do currículo nas salas de aula. Verificando-se uma verdadeira prática de avaliação formativa, a avaliação sumativa acaba por consistir num momento particularmente rico de integração e de síntese da informação recolhida acerca do que os alunos sabem e são capazes de fazer numa variedade de situaçóes. E isto significa que a informação obtida a partir dos processos decorrentes da avaliaçáo formativa náo pode deixar de ser devidamente considerada e integrada com outros que decorrem dos processos próprios da avaliação sumativa (por exemplo, um teste realizado com o propósito claro de fazer um balanço intermédio ou final relativamente a uma dada unidade curricular e que pode permitir o estabelecimento de referentes comuns a todos os alunos).

O que toda esta argumentação significa é que a avaliação formativa que, por natureza, acompanha os processos de aprendizagem, náo pode deixar de proporcionar informação de qualidade quanto ao desenvolvimento desses mesmos processos por parte dos alunos. O que não se pode é considerar que, nestas condiçôes, a avaliação formativa se transforma num conjunto de pequenas avaliações sumativas! Quando se verifica que um aluno não sabe o que é suposto saber, a avaliaçáo formativa deve estar presente para o ajudar a melhorar, a vencer a dificuldade, com o seu esforço 
e o esforço do professor. Ora, o que interessa ao professor, em termos de avaliação sumativa, em termos de balanço, não é o facto de um aluno não ter sabido algo num dado dia e, por isso, ser penalizado com uma informação negativa para efeitos desse mesmo balanço. $\mathrm{O}$ que verdadeiramente lhe interessa é saber: a) se o aluno ficou a saber; b) como é que ultrapassou as dificuldades; c) as razóes que poderão ter impedido que assim acontecesse; e d) o que foi efectivamente feito pelo aluno e pelo professor para dissipar as dificuldades.

Finalmente, ainda relativamente às relaçôes entre a avaliação formativa e a avaliação sumativa, para além do que já se referiu, é bom reiterar que não se devem confundir uma com a outra. Têm propósitos distintos, ocorrem em momentos distintos e têm uma inserção pedagógica distinta. Mas, acima de tudo, parece ser claro que a avaliação formativa alternativa e a avaliação sumativa têm pressupostos epistemológicos diferenciados. Basta pensarmos no papel e na participação dos alunos e dos professores num e noutro caso, no tipo de conhecimento que é gerado por uma e por outra e nos processos que geram esse mesmo conhecimento. Por isso não tenho facilidade em compreender a visão de que ambas são dimensóes distintas de um mesmo constructo. Talvez esta ideia se aplique bem à avaliação formativa e sumativa tal como foram conceptualizadas em 1967 por Scriven e nos anos 70 por Bloom e colaboradores (Scriven, 1967; Bloom; Hastings; Madaus, 1971). Mas o conceito de avaliação formativa evoluiu muito em relação a essa altura.

Por outro lado, também não me é fácil percepcioná-las numa visão dicotómica. Vejo-as mais numa relação complementar nos termos em que acima explicitei. Temos aqui, seguramente, um interessante tema para continuar a discussão, que merece ser aprofundada, nomeadamente tendo em conta os esforços de desenvolvimento teórico que têm vindo a ser concretizados no âmbito da avaliação formativa e a que já acima fiz referência.

\section{CONCLUSÕES E REFLEXÕES}

Há três resultados da investigação empírica sintetizados por Paul Black e Dylan Wiliam em 1998, que vale a pena recordar nesta altura:

1. Os alunos que frequentam salas de aula em que a avaliação é essencialmente de natureza formativa aprendem significativamente mais e melhor do que os alunos que frequentam aulas em que a avaliação é sobretudo sumativa.

2. Os alunos que mais se beneficiam da utilização deliberada e sistemática da avaliaçáo formativa são os alunos que têm mais dificuldades de aprendizagem. 
3. Os alunos que frequentam aulas em que a avaliação é formativa obtêm melhores resultados em exames externos do que os alunos que frequentam aulas em que a avaliação é sumativa.

Apesar destes resultados e da sua sólida base empírica, a verdade é que continua a ser difícil integrar as práticas de avaliação formativa nas salas de aula. Esta dificuldade é normalmente atribuída a razóes tais como: a) a formação dos professores; b) as dificuldades com a gestão do currículo; c) as concepções dos professores acerca da avaliação formativa; d) a organização e funcionamento das escolas; e) as pressóes da avaliaçáo externa; e f) a extensão dos programas escolares.

Neste artigo tem-se considerado que uma das razóes que também pode estar na origem das referidas dificuldades é a falta de clareza conceptual e de um sólido referencial teórico em que as práticas de avaliação formativa se possam apoiar. Nestas condiçóes, sugere-se a designação avaliação formativa alternativa para que fique claro que estamos a falar de uma avaliação realmente formativa, alternativa quer à avaliação formativa de matriz psicométrica, behaviourista e algo técnica, quer a todo o tipo de avaliaçóes ditas formativas mas que, na verdade, não passam de avaliaçóes de intenção ou de vontade formativa. Também se considera que o termo avaliação alternativa é pouco preciso, sendo desaconselhável a sua utilização sem que fique claro o seu significado.

Há um esforço a fazer no que se refere à clarificação do significado de termos que, por vezes, são utilizados indistintamente apesar de os conceitos que lhes são subjacentes terem significados muito diferentes. É, por exemplo, o caso de corrigir e de classificar ou de avaliar e classificar e de tantos outros. Ou o caso de designar um portefólio de trabalhos produzidos pelos alunos, uma composição, uma reacção crítica a um dado texto ou uma narrativa referente a uma visita de estudo, como instrumentos de avaliação. Penso que não se trata de uma questão de mera designação mas sim de uma questão epistemológica que tem relevância teórica. $\mathrm{Na}$ verdade, a designação instrumento surge no século XIX, na sequência do movimento taylorista da gestão científica das escolas; ou seja, num contexto em que predominava uma forte racionalidade técnica, em que avaliar e medir eram sinónimos. Consequentemente, um instrumento de avaliaçáo media exactamente as aprendizagens dos alunos, tal como um metro media exactamente o comprimento de um segmento de recta, ou um termómetro media exactamente a temperatura do corpo de um paciente. Julgo que designaçóes tais como tarefa de avaliação, método de avaliaçâo ou mesmo estratégia de avaliação poderão, na maioria dos casos, ser mais congruentes com a 
concepção de avaliação formativa alternativa que aqui se discutiu e definiu. Será que os próprios testes, quando lhes é dada uma utilização formativa, deverão ser designados como instrumentos? Julgo que se trata de uma questáo epistemológica e de coerência que deve existir entre os conceitos, os seus significados e as expressóes que utilizamos para os designar.

Outra questão que merece uma reflexão mais aprofundada é a que se refere às tradiçóes teóricas que foram brevemente discutidas neste artigo. Apesar de ser inegável a predominância da sua presença na literatura internacional, não se devem ignorar outras tradiçóes ou outras visóes. Assim, será interessante compreender outras contribuições e/ou tradiçôes europeias tais como a holandesa (Kleijne; Schuring, 1993; Lange, 1987, 1993) ou a talvez menos conhecida alemã (Koller, 2005), a de países nórdicos como a dinamarquesa (Jensen, 1993; Townshend; Moos; Skov, 2005) ou a finlandesa (Voogt; Kasurinem, 2005) e de países do sul da Europa como a espanhola (Rico, 1993; Rosales, 1984, 2000; Santos Guerra, 1995, 2003), a italiana (Bazzini, 1993; Looney; Laneve; Moscato, 2005) ou a portuguesa (Abrantes, 2002; Baptista, 1999; Cortesão, 1993; Cortesão; Torres, 1996; Fernandes, 1992, 2005, 2006a; Leal; Abrantes, 1990).

Não se podem igualmente ignorar importantes contributos teóricos que têm emergido em países da América do Sul como é o caso do Brasil (e.g., Demo, 1996; Gatti, 2002, 2003; Hoffmann, 2005; Luckesi, 1995; Romão, 2002, 2003; Sousa, 1995, 2003; Vasconcellos, 2005). Também neste caso é necessário estudar e compreender estes e outros contributos vindos de um país com tão fortes e significativas tradiçóes pedagógicas.

Neste artigo foram apenas destacadas as tradiçôes anglo-saxónica e francófona. A primeira, fortemente baseada na investigação empírica, com uma visão pragmática, pedagógica e muito associada ao currículo, da avaliação formativa. Trata-se de uma perspectiva que quase identifica avaliação formativa com feedback, tal é a relevância que dá às interacçóes sociais e culturais que ocorrem nas salas de aula, e que atribui ao professor um papel muito relevante quer no feedback, quer na regulação das aprendizagens e do ensino.

A tradição francófona está mais associada à concepção de modelos cognitivos das aprendizagens, realçando os processos de regulaçáo nos quais os alunos têm um papel primordial. A avaliação formativa está sobretudo associada à regulaçáo e à auto-regulação das aprendizagens; o feedback é apenas mais um elemento a considerar. O papel dos alunos é destacado, acentuando-se a importância da sua autonomia e do seu controlo sobre o que aprendem e como aprendem. 
Parece claro que é necessário conhecer e compreender outras tradições teóricas e práticas no domínio da avaliaçáo formativa que, tal como acima se referiu, se têm desenvolvido noutros contextos pedagógicos, sociais e políticos. Desta forma poderão desenvolver-se esforços que, por um lado, integrem as concepçóes teóricas actuais, dando-lhes outra abrangência, outro significado e outra profundidade, e que, por outro lado, permitam a partilha de abordagens que possibilitam a realização de investigação empírica.

Uma das questôes críticas mais relevantes aqui discutidas está relacionada com a definição da avaliação formativa alternativa. Tal como nos tem mostrado a investigação empírica, há ainda muitas concepçóes erradas acerca do que é a avaliação formativa. Isto é, concepções relativas à sua natureza, aos seus conteúdos, princípios, funções e relações com o ensino e a aprendizagem. É preciso sublinhar que a avaliação formativa de matriz construtivista/cognitivista ou sociocultural é alternativa a todas as avaliaçôes ditas formativas, que não são mais do que versóes mais ou menos formais, mais ou menos estruturadas, da avaliação formativa que foi conceptualizada nos anos 70 do século XX. Julgo que, a este respeito, muito há ainda a clarificar quer ao nível da comunidade dos investigadores, quer ao nível da formação inicial e contínua dos professores, quer ao nível dos diferentes níveis da administração da educação.

A avaliação formativa alternativa representa também uma tentativa de integrar perspectivas teóricas distintas. Neste aspecto o desafio consiste em conseguir compreender como é que, na prática, o conceito francófono de regulação e o conceito anglo-saxónico de feedback se articulam e fortalecem a principal função da avaliação formativa: melhorar as aprendizagens dos alunos.

Outras ideias debatidas neste artigo têm a ver com a necessidade de se estudarem e compreenderem as complexas relaçóes entre a avaliação formativa e a avaliação sumativa. Apesar de se sustentar a sua complementaridade, fica claro que é preciso perceber melhor a natureza de certas avaliaçóes sumativas e formativas ou então conceptualizar um terceiro tipo de avaliação.

O que parece decorrer desta discussão é a clara necessidade de a construçáo teórica se basear em investigaçóes empíricas que nos permitam descrever, analisar e interpretar um amplo conjunto de relaçóes, de fenómenos e de realidades associadas à avaliação formativa e à avaliação sumativa. Como referi noutro trabalho, as tarefas, os professores e os alunos são três elementos fundamentais que ocupam os vértices de uma espécie de triângulo em cujo interior estáo os contextos de ensino, de aprendizagem e de avaliaçáo gerados pelas interacçóes entre aqueles três elementos 
(Fernandes, 2006). Os contextos são temperados por múltiplos processos cognitivos, metacognitivos e sociais que interagem entre si tais como o feedback, a regulação feita por professores e alunos, a auto-regulação e a auto-avaliação.

A teoria da avaliaçáo no domínio das aprendizagens dos alunos tem que ser construída a partir do conhecimento que formos desenvolvendo acerca dos fenómenos que ocorrem no interior daquele triângulo e das interacçóes que se estabelecem entre os elementos dos seus vértices. Nestas condições parece prioritária a definição de linhas de trabalho investigativo que se centrem nas salas de aula e nas escolas e que nos permitam responder às questôes que têm vindo a ser formuladas, explícita ou implicitamente, ao longo deste artigo.

As respostas às questôes formuladas podem ser importantes contributos para que, por exemplo, a avaliação formativa deixe de ser apenas uma construção teórica e passe a integrar as práticas de professores e alunos nas salas de aula.

Uma das conclusóes a retirar deste trabalho, com base nos resultados da investigação empírica que se apresentaram, é a importância de se discutir como poderá estar ao alcance das escolas, dos professores e dos alunos melhorar $o$ que se aprende e como se aprende. Além disso, é bom sublinhar que a avaliação formativa, não sendo a panaceia para a resoluçáo de todos os problemas, é com certeza um processo pedagógico essencial para apoiar os alunos que, ano após ano, um pouco por todo o mundo, conhecem o desalento e/ou o abandono escolar. É por isso que me parece importante desbravar e aprofundar a ideia da avaliação formativa alternativa como uma das formas de enfrentar as questôes mais prementes e urgentes da educação contemporânea. E isso passa necessariamente pela construção teórica apoiada em investigação realizada em contextos reais. Porque é preciso compreender os fenómenos avaliativos com base na investigação das experiências vividas pelos seus principais intervenientes.

\section{REFERÊNCIAS BIBLIOGRÁFICAS}

ABRANTES, P. Introdução: a avaliação das aprendizagens no ensino básico. In: ABRANTES, P.; ARAÚJO, F. (Org.). Avaliação das aprendizagens: das concepções às práticas. Lisboa: Departamento da Educação Básica do Ministério da Educação, 2002. p. 9-15.

ABRECHT, R. L'Évaluation formative: une analyse critique. Bruxelles: De Boeck, 1991.
ALLAL, L. Estratégias de avaliação formativa: concepções psicopedagógicas e modalidades de aplicação. In: ALLAL, L.; CARDINET, J.; PERRENOUD, Ph. (Org.). A Avaliação formativa num ensino diferenciado. Coimbra: Almedina, 1986. p. 175-209.

ARCHBALD, D.; NEWMANN, F. Approaches to assessing academic achievement. In: BERLAK, 
$\mathrm{H}$. et al. Toward a new science of educational testing and assessment. Albany: State University of New York Press, 1992. p. 139-180.

BAPTISTA, J. A. Aprender por medida. Porto: Porto Editora, 1999.

BAZZINI, L. The Teaching/learning process and assessment practice: two intertwined sides of mathematics education. In: NISS, M. Cases of assessment in mathematics education: an ICMI study. Dordrecht: Kluwer, 1993. p. 99-106.

BERLAK, $H$. The Need for a new science of assessment. In: BERLAK, $\mathrm{H}$. et al. Toward a new science of educational testing and assessment. Albany: State University of New York Press, 1992a. p. 1-22.

. Toward the development of a new science of educational testing and assessment. In: BERLAK, $\mathrm{H}$. et al. Toward a new science of educational testing and assessment. Albany: State University of New York Press, 1992b. p. 181-206.

BIGGS, J. Assessment and classroom learning: a role for summative assessment? Assessment in Education: principles, policy \& practice, v.5, n.1, p. 103-110, 1998.

BLACK, P.; WILIAM, D. Assessment and classroom learning. Assessment in Education: principles, policy \& practice, v.5, n.1, p.7-74, 1998a.

. Assessment for learning in the classroom. In: GARDNER, J. Assessment and learning. London: Sage, 2006a. p. 9-25.

. Developing a theory of formative assessment. In: GARDNER, J. Assessment and learning. London: Sage, 2006b. p. 81-100.

.Inside the blackbox:raising standards

throughclassroomassessment. 1998b.Disponível em: < www.pdkintl.org/kappan/kbla9810.htm >. Acesso em: 22 out. 2004.

. The Reliability of assessments. In: GARDNER, J. Assessment and learning. London: Sage, 2006c. p. 119-131.

BLOOM, B.; HASTINGS, J.; MADAUS, G. Handbook of formative and summative evaluation of student learning. New York: Mac Graw Hill, 1971.
BONNIOL, J-J. Sur les regulations du fonctionnement cognitif de l'élève: contribution à une theorie de l'évaluation formative. In: ATELIER DE RECHERCHE SUR L'ÉVALUATION DES RÉSULTATS SCOLAIRES: motivations et réussite des élèves, 1989, Liège. Anais... Strasbourg: Conseil de L'Europe, 1989.

CARDINET, J. L'Apport sociocognitif à la régulation interactive. In: WEISS, J. L'évaluation: problème de communication. Cousset Fribourg: Delval, 1991. p. 199-213.

CORTESÃO, L. A Avaliação formativa: que desafios? Porto: ASA, 1993.

CORTESÃO, L.; TORRES, M. A. Avaliação pedagógica: mudança na escola, mudança na avaliação. Porto: Porto Editora, 1996.

DEMO, P. Avaliação sob o olhar propedêutico. São Paulo: Papirus, 1996.

EARL, L. Assessment as learning: using classroom assessment to maximize student learning. Thousand Oaks: Corwin Press, 2003.

FERNANDES, D. Avaliação das aprendizagens: desafios às teorias, práticas e políticas. Cacém: Texto Editores, 2005.

. Notes on the need for a theory of formative assessment. In: ENCONTRO ANUAL DA AMERICAN EDUCATIONAL RESEARCH ASSOCIATION. Chicago, 2007a.

- Para uma teoria da avaliação formativa. Revista Portuguesa de Educação, v.19, n.2, p. 21-50, 2006a.

- Vinte anos de avaliação das aprendizagens: uma síntese interpretativa de artigos publicados em Portugal. Revista Portuguesa de Pedagogia, v. 40, n.3, p. 289-348, 2006b.

. Vinte e cinco anos de avaliação das aprendizagens: uma síntese interpretativa de livros publicados em Portugal. In: ESTRELA, A. (Org.). Investigação em educação: teorias e práticas (1960-2005). Lisboa: Educa, 2007b. p. 261-306.

v.23, p. 18-21, 1992.

GARDNER, J. Assessment and learning. London: Sage, 2006a. 
GARDNER, J. Assessment and learning: an introduction. In: Assessment and learning. London: Sage, 2006b. p. 1-5.

GATTI, B. Avaliação educacional no Brasil: pontuando uma história de ações. Eccos Revista Científica Centro Universitário Nove de Julho, v.4, n.1, p.17-41, 2002. Disponível em: <http:// www.uninove.br/ojs/index.php/eccos/issue/ view/27/showtoc $>$. Acesso em: 22 jul. 2008.

. O Professor e a avaliação em sala de aula. Estudos em Avaliação Educacional, n.27, p. 97-114, 2003.

GIFFORD, B.; O'CONNOR, M. Changing assessments: alternative views of aptitude, achievement and instruction. Dordrecht: Kluwer, 1992.

GIPPS, C. Beyond testing: towards a theory of educational assessment. Londres: Falmer, 1994.

Socio-cultural aspects of assessment. Review of Research in Education, v.24, p. 355-392, 1999.

GIPPS, C.; STOBART, G. Alternative assessment. In: KELLAGHAN, T.; STUFFLEBEAM, D. International handbook of educational evaluation. Dordrecht: Kluwer, 2003. p. 549-576.

GOLDSTEIN, H. International comparisons of student attainment: some issues arising from the PISA study. Assessment in Education: principles, policy \& practice, v. 11, n. 3, p. 319330, 2004.

GRÉGOIRE, J. Évaluer des apprentissages: les apports de la psychologie cognitive. Bruxelles: De Boeck, 1996.

HADJI, C. L'Évaluation des actions éducatives. Paris: PUF, 1992.

HARLEN, W. On the relationship between assessment for formative and summative purposes. In: GARDNER, J. Assessment and learning. London: Sage, 2006. p. 103-118.

Teachers' summative practices and assessment for learning: tensinos and synergies. Curriculum Journal, v.16, n.2, p. 207223, 2005.

HARLEN, W.; JAMES, M. Assessment and learning: differences and relationships between formative and summative assessment. Assessment in education: principles, policy and practice, v. 4, n. 3, p. 365-379, 1997.

HOFFMANN, J. O Jogo do contrário em avaliação. Porto Alegre: Mediação, 2005.

JENSEN, $\mathrm{H}$. Assessment of primary and lower secondary mathematics in Dennmark. In: NISS, M. Cases of assessment in mathematics education: an ICMI study. Dordrecht: Kluwer, 1993. p. 119-128.

KELLAGHAN, T. Local, national, and international levels of system evaluation: introduction. In: KELLAGHAN, T.; STUFFLEBEAM, D. International handbook of educational evaluation. Dordrecht: Kluwer, 2003. p. 873-882.

KLEIJNE, W.; SCHURING, H. Assessment of examinations in the Netherlands. In: NISS, M. Cases of assessment in mathematics education: an ICMI study. Dordrecht: Kluwer, 1993. p. 139154.

KOLLER, O. Formative assessment in classrooms: a review of the empirical German literature. In: Formative assessment: improving learning in secondary schools. Paris: OECD Publishing, 2005. p. 265-275.

LANGE, Jan de. Assessment in problemoriented curricula. In: WEBB, N.; COXFORD, A. Assessment in the mathematics classroom. Reston: NCTM, 1993. p. 197-208. .Mathematics, insight and meaning. Holanda: OweOC, 1987.

LEAL, L.; ABRANTES, P. Avaliação da aprendizagem/avaliação na aprendizagem. Inovação, v.3, n.4, p. 65-75, 1990.

LOONEY, J.; LANEVE, C.; MOSCATO, M. A System in transition. In: Formative assessment: improving learning in secondary schools. Paris: OECD Publishing, 2005. p. 163176.

LUCKESI, C. Avaliação da aprendizagem escolar. São Paulo: Cortez, 1995.

NUNZIATI, G. Pour construire un dispositif d'évaluation formatrice. Cahiers Pedagogiques, 
n. 280, p. 47-64, 1990.

PERRENOUD, Ph. L'Évaluation des élèves: de la fabrication de l'excellence à la régulation des apprentissages. Bruxelles: De Boeck, 1998a.

. From formative evaluation to a controlled regulation of learning processes: towards a wider conceptual field. Assessment in Education: principles, policy \& practice, v.5, n.1, p. 85-102, 1998 b.

RICO, L. Mathematics assessment in the Spanish education system. In: NISS, M. Cases of assessment in mathematics education: an ICMI study. Dordrecht: Kluwer, 1993. p. 9-20.

RILEY, K.; TORRANCE, H. Big change questions. Journal of Educational Change, v.4, p. 419-425, 2003.

ROMÃO, J. E. Avaliação: exclusão ou inclusão? Eccos Revista Científica Centro Universitário Nove de Julho, v. 4, n.1, p. 43-60, 2002. Disponível em: <http://www.uninove.br/ojs/index.php/eccos/ issue/view/27/showToc>. Acesso em: 22 jul. 2008.

Avaliação dialógica: desafios e perspectivas. 5. ed. São Paulo: Cortez, 2003.

ROSALES, C. Criterios para una evaluación formativa. 2. ed. Madrid: Narcea, 1984.

- Evaluar es reflexionar sobre la enseñanza. 3. ed. Madrid: Narcea, 2000.

SADLER, D. Formative assessment: revisiting the territory. Assessment in Education: principles, policy \& practice, v. 5, n. 1, p. 7784, 1998.

Formative assessment and the design of instructional systems. Instructional Science, v.18, p. 119-144, 1989.

SANTOS GUERRA, M. La Evaluación: un proceso de diálogo, comprensión y mejora. Málaga: Aljibe, 1995.

Una flecha en la diana: la evaluación como aprendizaje. Madrid: Narcea, 2003.

SCRIVEN, M. The Methodology of evaluation. Chicago: Rand McNally, 1967.

SEBBA, J. Policy and practice in assessment for learning: the experience of selected OECD countries. In: GARDNER, J. Assessment and learning. London: Sage, 2006. p. 185-196.

SHEPARD, L. The Role of assessment in a learning culture. Educational Researcher, v. 29, n. 7, p. 4-14, 2000.

. The Role of classroom assessment in teaching and learning. In: RICHARDSON, V. Handbook of research on teaching. 4.ed. New York: Macmillan, 2001. p. 1066-1101.

SOUSA, S. Avaliação da aprendizagem nas pesquisas no Brasil de 1930 a 1980. Cadernos de Pesquisa, n. 94, p. 43-49, 1995.

Possíveis impactos das políticas de avaliação no currículo escolar. Cadernos de Pesquisa. n.119, p. 175-190, 2003.

STIGGINS, R. Assessment crisis: the absence of assessment for learning. 2002. Disponível em: < www.pdkintl.org/kappan/k0206sti.htm >. Acesso em: 24 set. 2004.

. New assessment beliefs for a new school mission. Phi Delta Kappan, v. 86, n. 1, p. 22-27, 2004.

STIGGINS, R.; CONKLIN, N. In teachers' hands: investigating the practices of classroom assessment. Albany: State University of New York Press, 1992.

STOBART, G. The validity of formative assessment. In: GARDNER, J. Assessment and learning. London: Sage, 2006. p. 133-146.

TELLEZ, K. Authentic assessment. In: SIKULA, J. Handbook of research on teacher education. 2.ed. New York: Macmillan, 1996. p. 704-721. TOWNSHEND, J.; MOOS, L.; SKOV, P. Building on a tradition of democracy and dialogue in schools. In: Formative assessment: improving learning in secondary schools. Paris: OECD Publishing, 2005. p. 117-128.

VASCONCELLOS, C. Avaliação da aprendizagem: práticas de mudança por uma práxis transformadora. 7. ed. São Paulo: Libertad, 2005.

VIEIRA, I. O Feedback nas práticas avaliativas de dois professores de Português do ensino secundário. Lisboa, 2007. Tese (Mestrado em Ciências da Educação) Faculdade de Psicologia e de Ciências da Educação, Universidade de Lisboa. 
VOOGT, J.; KASURINEM, H. Emphasising development instead of competition and comparison. In: assessment: improving learning in secondary schools. Paris: OECD Publishing, 2005. p. 149162.

WIGGINS, G. Educative assessment. San
Francisco: Jossey-Bass, 1998.

. Teaching to the authentic test. Educational Leadership, v. 46, n.7, p. 41-47, 1989a.

. A True test: toward more authentic and equitable assessment. Phi Delta Kappa, v. 70, p. 703-714, 1989b.

Recebido em: agosto 2008

Aprovado para publicação em: setembro 2008 